\title{
LncRNAs and cancer (Review)
}

\author{
RUI ZHANG ${ }^{*}$, LI QIONG XIA*, WEN WEN LU, JING ZHANG and JIN-SHUI ZHU \\ Department of Gastroenterology, Shanghai Jiao Tong University Affiliated Shanghai Sixth People's Hospital, \\ Shanghai 200233, P.R. China
}

Received January 9, 2015; Accepted February 11, 2016

DOI: $10.3892 / \mathrm{ol} .2016 .4770$

\begin{abstract}
Long non-coding RNAs (lncRNAs) are a group of non-coding RNAs composed of $>200$ nucleotides. Recent studies have revealed that lncRNAs exert an important role in the development and progression of cancer. In this review, the involvement of the most extensively investigated lncRNAs in cancers of the digestive, respiratory, reproductive, urinary and central nervous systems are discussed. LncRNAs function via molecular and biochemical mechanisms that include cis- and trans-regulation of gene expression, epigenetic modulation in the nucleus and post-transcriptional control in the cytoplasm. Although the detailed biological functions and molecular mechanisms of the majority of lncRNAs remain to be elucidated, this review aims to provide a novel insight into the diagnosis and treatment of cancer using lncRNAs.
\end{abstract}

\section{Contents}

1. Introduction

2. Structure and function of lncRNAs

3. Cancer-related lncRNAs

4. Conclusion

\section{Introduction}

In the human genome, $\leq 2 \%$ of protein-coding genes are stably transcribed; the remaining RNAs exhibit no protein-coding function. These non-coding RNAs (ncRNAs) include small interfering RNAs (siRNAs), microRNAs (miRNAs), PIWI-interacting RNAs and long ncRNAs (lncRNAs) (1).

Correspondence to: Professor Jin-Shui Zhu or Dr Jing Zhang, Department of Gastroenterology, Shanghai Jiao Tong University Affiliated Shanghai Sixth People's Hospital, 600 Yishan Road, Shanghai 200233, P.R. China

E-mail: zhujs1803@163.com

E-mail: jing5522724@163.com

*Contributed equally

Key words: long non-coding RNA, HOTAIR, MALAT1, cancer
LncRNAs are a group of non-coding RNAs composed of $>200$ nucleotides (2). Originally, lncRNAs were considered to be the product of evolutionary junk or transcriptional noise, however, IncRNAs have been demonstrated to exhibit a variety of functions, including chromatin remodeling, mRNA splicing and editing and transcriptional regulation. LcnRNAs may upregulate or downregulate gene expression both transcriptionally and post-transcriptionally. LncRNAs exert a key role in numerous cellular processes, including cell growth, apoptosis and carcinogenesis $(3,4)$ and thus, they are implicated in the progression of various types of human cancer (5). In the present review, the most important and well-known lncRNAs in cancers are discussed and their known and possible molecular functions are outlined briefly, as well as their potential application as therapeutic targets or biomarkers.

\section{Structure and function of IncRNAs}

Structure of IncRNAs. LncRNAs are endogenous RNA molecules, which contain 200-100,000 nucleotides. Approximately 7,000-23,000 lncRNAs have been identified in vivo, which is significantly higher than the number of protein-coding genes that have been found. LncRNAs exhibit an mRNA-like structure with a poly (A) tail in certain cases. The promoters of lncRNAs may also bind to transcription factors (TFs), such as Oct3/4 and Nanog.

Based on their location with respect to protein-coding genes, lncRNAs may be classified into the following five groups: i) Intergenic lncRNAs (lincRNA): Located between two protein-coding genes; ii) intronic lncRNAs: Transcribed from the introns of protein-coding genes; iii) overlapping lncRNAs: Contain a coding gene within an intron on the same strand; iv) antisense lncRNAs: Transcribed from the opposite of the protein-coding strand; v) processed lncRNAs: Do not contain an open reading frame (ORF) (6).

Function of IncRNAs. LncRNAs lack a significant ORF and protein-coding function, and are involved in the regulation of gene expression at the epigenetic, transcriptional and post-transcriptional levels in the form of RNA (7). LncRNAs regulate gene expression and chromatin structure in the following ways: i) Decoy effect: Binding to other RNAs and proteins to alter their functions; ii) scaffold effect: Connecting chromatin modified proteins and DNA regions to form signal connections; iii) post-transcriptional effect: Forming RNA dimers with mRNA sequences to block transcription-associated sites, 
subsequently regulating the stability, cleavage and translation of protein-coding genes (6). Wilusz et al (8) reported that lncRNAs exhibit the following effects: i) Targeting proteins to specific genomic loci to affect transcription patterns; ii) modulating the activity of protein-binding partners; iii) acting as precursors for small RNAs; iv) affecting the processing of other RNAs; v) forming nucleic acids and protein complexes with protein as structural RNAs. In general, $\operatorname{lncRNAs}$ regulate gene expression by altering chromatin structure, silencing or activating a gene or a gene family and in certain cases whole chromosomes via cis- or trans-methods (direct regulation of an adjacent gene or indirect regulation via a gene product, respectively).

LncRNA databases. As the number of identified lncRNAs has increased, databases for lncRNAs have been established. These databases include existing lncRNAs and information regarding their known molecular/cellular function, revealing associations between lncRNAs and other RNAs. LncRNA information is also combined with other proteomic and genomic information. Key lncRNA databases are listed in Table I (9).

\section{Cancer-related IncRNAs}

A significant association between cancer and lncRNAs has been identified as a result of disease state studies, which have investigated the function of lncRNAs in development and cellular differentiation (10).

To investigate the association between a specific lncRNA and a certain type of cancer, the expression levels of lncRNA in adjacent normal tissues and cancer tissues, as well as normal and cancer cell lines must be compared by reverse transcription-quantitative polymerase chain reaction (RT-qPCR). In vitro and in vivo assays may also be performed to identify the lncRNA's involvement in tumor progression, including cell proliferation, migration, invasion, apoptosis and cell cycle assays. Statistical analysis is also required to investigate the association between lncRNA expression levels and the overall survival rates of cancer patients. The primary cancer-associated lncRNAs are discussed below and listed in Table II.

Digestive system cancers. Taurine-upregulated gene 1 (TUG1) is significantly overexpressed in esophageal squamous cell carcinoma (ESCC) tissues, and silencing TUG1 in vitro using siRNA inhibits the proliferation and migration of ESCC cells and blocks the progression of the cell cycle (11). Furthermore, high TUG1 expression is associated with a family history of ESCC and upper segmental esophageal cancer occurring between the esophageal inlet and upper edge of the manubrium (11). Linc-POU class 3 homeobox 3 (POU3F3) has been characterized as a highly conserved functional transcription regulator in ESCC, which promotes the methylation of POU3F3 by interacting with EZH2 $(12,13)$.

LINC00152 may also be identified in the plasma of cancer patients, and the levels of plasma LINC00152 have been shown to be significantly elevated in gastric cancer (GC) patients (14). Plasma LINC00152 is protected by exosomes and may exist stably in blood, suggesting it may present a potential novel
Table I. Databases for lncRNAs.

\begin{tabular}{|c|c|}
\hline Database & Website \\
\hline CHIPBase & deepbase.sysu.edu.cn/chipbase \\
\hline DIANA-LncBase & $\begin{array}{l}\text { http://diana.imis.athena-innovation } \\
\text { gr/DianaTool }\end{array}$ \\
\hline LNCipedia & www.lncipedia.org \\
\hline $\operatorname{lncRNAdb}$ & www.lncrnadb.org \\
\hline lncRNAdisease & cmbi.bjmu.edu.cn/lncrnadisease \\
\hline lncRNome & genome.igib.res.in/lncRNome \\
\hline Noncode v3.0 & $\begin{array}{l}\text { www.ebi.ac.uk/miriam/main/ } \\
\text { collections/MIR:00000248 }\end{array}$ \\
\hline $\begin{array}{l}\text { The functional } \\
\text { lncRNA database }\end{array}$ & www.valadkhanlab.org \\
\hline
\end{tabular}

The known functions of lncRNAs may be obtained from the listed databases (9).

blood-based biomarker for the diagnosis of GC (14). Gastric adenocarcinoma predictive long intergenic noncoding RNA (GAPLINC) regulates CD44-dependent cell invasiveness and is associated with a poor prognosis of GC. GAPLINC regulates CD44 as a molecular decoy for miR211-3p, a miRNA that targets CD44 and GAPLINC (15). LncRNA plasma-cytoma variant translocation 1 (PVT1) expression has been found to correlate with lymph node invasion of GC and is highly expressed in paclitaxel-resistant SGC7901 cells (16). In addition, increased expression of HOX antisense intergenic RNA (HOTAIR) is observed in gastric cardia adenocarcinoma (GCA) tissues when compared with normal tissues (17). HOTAIR expression is also associated with poor survival rates in GCA patients. The single nucleotide polymorphism, rs12826786, may increase the risk of developing GCA by influencing the expression of HOTAIR (17). FENDRR is an lncRNA that binds to polycomb repressive complex 2 (PRC2) to epigenetically regulate the expression of its target gene. The FENDRR gene is 3,099 nucleotides in length and is located at chr3q13.31, consisting of four exons. FENDRR suppresses tumor invasion and lymphatic metastasis in GC via the downregulation of fibronectin 1 and matrix metalloproteinase (MMP)2/MMP9 expression (18). Furthermore, lncRNA AC138128.1 may present a novel biomarker for predicting GC development (19).

HOTAIR, which is encoded in the antisense direction from the HOXC gene cluster and induces transcriptional silencing of HOXD genes through interaction and recruitment of the PRC2 (20), has been shown to be involved in tumor pathogenesis, acting as a promoter in the carcinogenesis of colorectal cancer. Furthermore, it is predictive of poor prognosis in colorectal cancer (20). Recently, a two-stage case-control study revealed that patients with the rs7958904 CC genotype exhibited a significantly decreased risk of both Dukes' stage I and II colorectal cancer compared with those exhibiting the GG genotype, indicating that genetic variations in the HOTAIR gene are associated with the risk of colorectal cancer (21). An additional study indicated that HOTAIR and IncRNA-422 may be involved in 
carcinogenesis by regulating protein-coding genes involved in specific biological processes associated with colorectal cancer (22). Furthermore, HOTAIR and lncRNA-422 are upregulated when KRAS is overexpressed, but downregulated when Janus-kinase 2 or TANK-binding kinase 1 are knocked out and when platelet-derived growth factor is overexpressed (22). Cancer susceptibility candidate 2 (CASC2) and growth arrest-specific transcript 5 (GAS5) are known tumor suppressors in colorectal cancer $(23,24)$. Colony formation assays have shown that the expression levels of R05532, NR_015441 and NR_033374 positively correlate with radiation resistance, indicating that these IncRNAs may be present predictive markers of radiosensitivity of colorectal cancer (25).

The lincRNA-ubiquitin-fold modifier conjugating enzyme 1, whose stability is reduced by miRNA 34a, promotes proliferation, cell cycle progression and inhibits apoptosis in hepatocellular carcinoma (HCC) cells. Its expression is associated with tumor size, Barcelona clinic liver cancer stage and patient outcome (26). It also regulates $\beta$-catenin expression in HCC cells by interacting directly with the mRNA stabilizing protein, HuR (26). In addition, metallothionein 1D pseudogene (MT1DP) acts as a tumor suppressor in HCC. MT1DP negatively regulates $\alpha$-fetoprotein, a liver cancer tumor marker, by inhibiting protein synthesis of forkhead box A1, an important TF in liver development and cancer progression (27). Furthermore, the IncRNA-low expression in tumor (LET), a newly identified lncRNA, is downregulated in HCC (28).

Metastasis-associated lung adenocarcinoma transcript 1 (MALAT1), is a nuclear lincRNA composed of $>8,000$ nucleotides that is transcribed from chromosome 11q13 (1). MALAT1 is highly expressed in pancreatic cancer and has been found to correlate with clinical stage, tumor size, lymph node metastasis and distant metastasis in pancreatic cancer patients (29). Downregulation of MALAT1 inhibits tumor cell proliferation and decreases cell migration and invasion in vitro (30). These underlying mechanisms are involved in inducing $\mathrm{G}_{2} / \mathrm{M}$ cell cycle arrest, promoting cell apoptosis, suppressing epithelial-mesenchymal transition (EMT) and reducing cancer stem-like properties (30). LncRNA highly up-regulated in liver cancer exhibits similar functions to MALAT1 (31). LncRNA BC008363 exhibits tumor suppressor activity in pancreatic cancer (32). Furthermore, LncRNA-LET has been identified as a tumor suppressor and a positive prognostic factor in gallbladder cancer (28).

Respiratory system cancers. A number of lncRNAs are significantly upregulated or downregulated in non-small cell lung cancer (NSCLC). Among these, RP11-385J1.2 and TUBA4B are the most common aberrantly expressed lncRNAs, as shown by RT-qPCR in NSCLC, which indicates that lncRNAs may exhibit an important role in the development of NSCLC (33). LncRNA PVT1 expression has been found to correlate with histological grade, lymph node metastasis and overall survival in NSCLC (34). Cheng et al (35) reported that IncRNA expression was correlated with epidermal growth factor receptor tyrosine kinase inhibitor (EGFR-TKI) resistance in NSCLC cells. A recent study revealed that HOTAIR is involved in lung carcinogenesis induced by cigarette smoke extract (36). An additional study reported that
HOTAIR promotes proliferation, invasion, metastasis and drug resistance in lung cancer cells (37). Notably, MALAT1 enhances brain metastasis by inducing EMT in NSCLC (38). Cancer-associated region lncRNA (CARLo-5) also promotes NSCLC progression, and inhibition of CARLo-5 by siRNA suppresses proliferation, migration and invasion in NSCLC cell lines (39).

Reproductive system cancers. HOTAIR is highly expressed in endometrial cancer cells and tissues. Downregulation of HOTAIR expression results in a significant inhibition of endometrial cancer cell proliferation, migration and invasion by inducing cell cycle arrest at $G_{0} / G_{1}$ phase, indicating that HOTAIR may present a key regulator of endometrial cancer (40). CASC2 functions as a tumor suppressor in endometrial cancer (23).

In addition, HOTAIR promotes the progression of human cervical cancer via the upregulation of vascular endothelial growth factor, MMP-9 and EMT-related gene expression, which are important for cell motility and metastasis (41). An additional lncRNA, GAS5, is also associated with cervical cancer; decreased GAS5 expression has been found to significantly correlate with International Federation of Gynecology and Obstetrics stage, vascular invasion, lymph node metastasis and overall survival (42).

IRAIN is an intragenic lncRNA within the insulin-like growth factor type I receptor locus with monoallelic expression from the paternal allele (43). IRAIN is aberrantly expressed in both tumors and peripheral blood leukocytes in breast cancer (BC) (43). Analysis of IncRNAs in human BC clinical subtypes revealed that HOTAIR is significantly overexpressed in the human epidermal growth factor receptor 2-enriched subgroup, while HOTAIRM1 is overexpressed in the basal-like subgroup (44). A novel lncRNA, BC040587, which is found at the 3 q13.31 locus, a chromosomal region comprised of cooperatively acting tumor suppressor genes, exhibits frequent copy number alterations and is associated with BC (45). BC040587 expression is downregulated in BC samples and cell lines (45). Low expression of BC040587 is associated with a worse prognosis (45). Human ovarian cancer-specific transcript 2 promotes cell proliferation, migration and invasion in epithelial ovarian cancer by binding to miRNA let-7b, a potential tumor suppressor (46).

Urinary system cancers. MALAT1 is highly expressed in clear cell renal cell carcinoma (ccRCC) tissues and renal cancer cells when compared with adjacent non-tumor tissues, and has been found to correlate with cell proliferation, migration and invasion in ccRCC (47). According to Zhang et al (3), SPRY4-IT1 and MALAT1 exhibit identical functions, indicating that SPRY4-IT1 may present a potential prognostic biomarker and therapeutic target of ccRCC (3).

At present, prostate cancer gene antigen 3 (PCA3) is one of the most extensively studied prostate cancer-specific lncRNAs. A short tandem repeat polymorphism, TAAA, in the promoter region of the PCA3 gene has been shown to be a risk-increasing factor for prostate cancer in the Chinese population $(48,49)$. PCA3, C20orf166-AS1 and RP11-267A15.1 are considered prostate cancer-specific lncRNAs as they exhibit significant differential expression in prostate cancer tissues (50). LncRNA 
Table II. LncRNAs associated with cancer.

\begin{tabular}{|c|c|c|c|c|}
\hline Cancer type & $\operatorname{lncRNA}$ & Expression & Functions & $\operatorname{Ref}(s)$. \\
\hline \multirow[t]{2}{*}{ ESCC } & TUG1 & $\uparrow$ & Promoting proliferation, migration, cell cycle & $(11)$ \\
\hline & linc-POU3F3 & $\uparrow$ & Promote DNA methylation & $(12,13)$ \\
\hline \multirow[t]{6}{*}{ Gastric cancer } & LINC00152 & $\uparrow$ & Promoting cancer progression & $(14)$ \\
\hline & GAPLINC & $\uparrow$ & Promoting invasion & $(15)$ \\
\hline & PVT1 & $\uparrow$ & Promoting lymph node invasion and paclitaxel resistance & $(16)$ \\
\hline & HOTAIR & $\uparrow$ & Promoting cancer occurrence and progression & $(17)$ \\
\hline & FENDRR & $\downarrow$ & Suppressing invasion, lymphatic metastasis & $(18)$ \\
\hline & AC138128.1 & $\downarrow$ & Suppressing cancer progression & (19) \\
\hline \multirow[t]{5}{*}{ Colorectal cancer } & HOTAIR & $\uparrow$ & Promoting cancer occurrence, progression & $(21,22)$ \\
\hline & lncRNA-422 & $\uparrow$ & Promoting cancer progression & $(22)$ \\
\hline & $\begin{array}{l}\text { R05532, NR_015441, } \\
\text { NR_033374 }\end{array}$ & $\uparrow$ & Promoting radiation resistance & $(25)$ \\
\hline & CASC2 & $\downarrow$ & Suppressing cancer progression & $(23)$ \\
\hline & GAS5 & $\downarrow$ & Suppressing cell proliferation & (24) \\
\hline \multirow{3}{*}{$\begin{array}{l}\text { Hepatocellular } \\
\text { carcinoma }\end{array}$} & UFC1 & $\uparrow$ & Promoting proliferation, cell cycle and inhibiting apoptosis & $(26)$ \\
\hline & MT1DP & $\downarrow$ & Suppressing cancer progression & $(27)$ \\
\hline & IncRNA-LET & $\downarrow$ & Suppressing cancer progression & $(28)$ \\
\hline \multirow[t]{3}{*}{ Pancreatic cancer } & MALAT1 & $\uparrow$ & Promoting proliferation, migration and invasion & $(29,30)$ \\
\hline & HULC & $\uparrow$ & Promoting proliferation, migration, invasion & (31) \\
\hline & BC008363 & $\downarrow$ & Suppressing cancer progression & $(32)$ \\
\hline \multirow{7}{*}{$\begin{array}{l}\text { Gallbladder cancer } \\
\text { NSCLC }\end{array}$} & lncRNA-LET & $\downarrow$ & Suppressing proliferation and invasion & $(28)$ \\
\hline & RP11385J1.2, & & Unknown & (33) \\
\hline & TUBA4B & & Unknown & (33) \\
\hline & PVT1 & $\uparrow$ & Promoting proliferation, migration, invasion & (34) \\
\hline & HOTAIR & $\uparrow$ & $\begin{array}{l}\text { Promoting proliferation, invasion, migration, and drug } \\
\text { resistance }\end{array}$ & $(36,37)$ \\
\hline & MALAT1 & $\uparrow$ & Promoting brain metastasis & (38) \\
\hline & CARLo-5 & $\uparrow$ & Promoting proliferation, migration, invasion & (39) \\
\hline \multirow[t]{2}{*}{ Endometrial carcinoma } & HOTAIR & $\uparrow$ & Promoting proliferation, migration, invasion and cell cycle & $(40)$ \\
\hline & CASC2 & $\downarrow$ & Suppressing cancer progression & (23) \\
\hline \multirow[t]{2}{*}{ Cervical cancer } & HOTAIR & $\uparrow$ & Promoting proliferation, migration, invasion & $(41)$ \\
\hline & GAS5 & $\downarrow$ & Suppressing cancer progression & $(42)$ \\
\hline \multirow[t]{4}{*}{ Breast cancer } & IRAIN & & Aberrantly expressed & (43) \\
\hline & HOTAIR & $\uparrow$ & Promoting HER2-enriched subgroup progression & \\
\hline & HOTAIRM1 & $\uparrow$ & Promoting basal-like subgroup progression & $(44)$ \\
\hline & ВC040587 & $\downarrow$ & Suppressing cancer progression & $(45)$ \\
\hline \multirow{3}{*}{$\begin{array}{l}\text { Ovarian cancer } \\
\text { ccRCC }\end{array}$} & HOST2 & $\uparrow$ & Promoting proliferation, migration, invasion & $(46)$ \\
\hline & MALAT1 & $\uparrow$ & Promoting proliferation, migration, invasion & $(47)$ \\
\hline & SPRY4-IT1 & $\uparrow$ & Promoting proliferation, migration, invasion & (3) \\
\hline \multirow[t]{6}{*}{ Prostate cancer } & ENSG00000261777 & & Unknown & $(5)$ \\
\hline & PCA3 & $\uparrow$ & Increasing the risk of PCA & $(48,50)$ \\
\hline & C20orf166-AS1 & & Unknown & $(50)$ \\
\hline & RP11-267A15.1 & & & \\
\hline & PCAT-1 & $\uparrow$ & Promoting proliferation & $(51)$ \\
\hline & NEAT1 & $\uparrow$ & Promoting cancer progression & $(52)$ \\
\hline Bladder cancer & GHET1 & $\uparrow$ & Promoting proliferation and invasion & $(53)$ \\
\hline \multirow[t]{3}{*}{ Glioma } & HOTAIR & $\uparrow$ & Promoting cell cycle & (54) \\
\hline & uc.283-plus & $\uparrow$ & Promoting cancer progression & $(55)$ \\
\hline & linc-POU3F3 & $\uparrow$ & promoting cell viability and proliferation & $(12)$ \\
\hline CASC2 & & $\downarrow$ & $\begin{array}{l}\text { Suppressing proliferation, migration, invasion and } \\
\text { promoting cell apoptosis }\end{array}$ & (23) \\
\hline
\end{tabular}


Table II. Continued.

\begin{tabular}{|c|c|c|c|c|}
\hline Cancer type & lncRNA & Expression & Functions & $\operatorname{Ref}(s)$. \\
\hline APL & NEAT1 & $\downarrow$ & Promoting myeloid differentiation & $(56)$ \\
\hline Multiple myeloma & MALAT1 & $\uparrow$ & Promoting cancer progression & $(57)$ \\
\hline Osteosarcoma & $\begin{array}{l}\text { MALAT1 } \\
\text { BC040587 }\end{array}$ & $\begin{array}{l}\uparrow \\
\downarrow\end{array}$ & $\begin{array}{l}\text { Promoting proliferation and metastasis } \\
\text { Suppressing cancer progression }\end{array}$ & $\begin{array}{l}(58) \\
(59)\end{array}$ \\
\hline $\begin{array}{l}\text { Thyroid carcinoma } \\
\text { Melanoma }\end{array}$ & $\begin{array}{c}\text { BANCR } \\
\text { BANCR } \\
\text { SPRY4-IT1 }\end{array}$ & $\begin{array}{l}\uparrow \\
\uparrow \\
\uparrow\end{array}$ & $\begin{array}{l}\text { Promoting proliferation, activating autophagy } \\
\text { Promoting migration } \\
\text { Promoting proliferation and invasion, suppressing } \\
\text { apoptosis }\end{array}$ & $\begin{array}{l}(60) \\
(61) \\
(62)\end{array}$ \\
\hline \multicolumn{5}{|c|}{$\begin{array}{l}\downarrow \text {, downregulated; } \uparrow \text {, upregulated. lncRNA, long non-coding RNA; TUG1, taurine-upregulated gene 1; POU3F3, POU class } 3 \text { homeobox } 3 \text {; } \\
\text { GAPLINC, gastric adenocarcinoma predictive long intergenic noncoding RNA; PVT1, plasma-cytoma variant translocation 1; HOTAIR, } \\
\text { HOX antisense intergenic RNA; CASC2, cancer susceptibility candidate 2; GAS5, growth arrest-specific transcript 5; UFC1, ubiquitin-fold } \\
\text { modifier conjugating enzyme 1; MT1DP, metallothionein 1D pseudogene; LET, low expression in tumor; MALAT1, metastasis-associated } \\
\text { lung adenocarcinoma transcript 1; HULC, hepatocellular carcinoma up-regulated long non-coding RNA; TUBA4B, tubulin } \alpha \text { 4b; CARLo-5, } \\
\text { cancer-associated region lncRNA; PCA3, prostate cancer gene antigen 3; NEAT1, nuclear enriched abundant transcript 1; GHET1, gastric } \\
\text { carcinoma high expressed transcript 1; BANCR, BRAF-activated lncRNA; ESCC, epithelial squamous cell carcinoma; NSCLC, non-small } \\
\text { cell lung carcinoma; ccRCC, clear cell renal cell carcinoma; APL, acute promyelocytic leukemia; HER2, human epidermal growth factor } \\
\text { receptor } 2 \text {. }\end{array}$} \\
\hline
\end{tabular}

ENSG00000261777 shares an intron with DEAD-box helicase DDX19 and interacts with insulin-like growth factor $2 \mathrm{P} 1$, indicating its involvement in prostate cancer (5). PCAT-1-mediated proliferation is dependent on cMyc protein stabilization. The PCAT-1-cMyc relationship is mediated via the post-transcriptional activity of the MYC 3' untranslated region. However, stabilization of $\mathrm{cMyc}$ may be reversed by targeting PCAT-1 with miR-3667-3p, indicating that the lncRNA PCAT-1 may promote prostate cancer proliferation via cMyc (51). Nuclear enriched abundant transcript 1 (NEAT1) is also overexpressed in prostate cancer (52).

Recently, a study demonstrated that gastric carcinoma high expressed transcript 1 (GHET1) is upregulated in bladder cancer tissue compared with adjacent normal tissues, and is correlated with tumor size, advanced tumor, lymph node status and poor survival (53). GHET1 knockdown suppresses the proliferation and invasion of bladder cancer cells and inhibiting the expression of GHET1 reverses EMT in bladder cancer cells (53).

Central nervous system cancers. HOTAIR promotes cell cycle progression in human glioma by binding its 5 ' domain to the PRC2, and is closely associated with glioma stage and poor prognosis (54). Additionally, the uc.283-plus IncRNA may be important in the biology of glioma (55). Overexpression of linc-POU3F3 increases cell viability and proliferation in glioma (12). However, overexpression of CASC2 inhibits the malignancy of glioma cells via negatively regulating miR-21, subsequently affecting proliferation, migration, invasion and cellular apoptosis (23).

Other cancers. NEAT1, an IncRNA essential for the formation of nuclear body paraspeckles, is important in myeloid differentiation. It is inhibited in acute promyelocytic leukemia patients by promyelocytic leukemia/retinoic acid receptor $\alpha(56)$.
The expression of MALAT1 has been found to strongly correlate with disease status in multiple myeloma. The extent of changes in MALAT1 expression after treatment has prognostic relevance, with increased expression associated with poorer prognosis (57).

MALAT1 promotes the proliferation and metastasis of osteosarcoma cells by activating the phosphoinositide 3-kinase/Akt pathway (58). Notably, genetic deletion of $\mathrm{BC} 040587$ is associated with poor survival of osteosarcoma patients (59).

BRAF-activated lncRNA (BANCR) is overexpressed in papillary thyroid carcinoma (PTC). It may increase cell proliferation and activate autophagy in PTC (60).

Additionally, BANCR is overexpressed in melanoma. It promotes the migration of melanoma cells via the upregulation of CXCL11, an important gene that is involved in cell migration (61). Furthermore, the expression of SPRY4-IT1 is increased in melanoma cells (62). LncRNAs may also be associated with head and neck squamous cell carcinoma (63) and laryngeal squamous cell cancer (64).

\section{Conclusion}

LncRNAs exhibit an important role in a number of cancers and thus, they may be used as biomarkers for predicting recurrence and prognosis and may subsequently present potential therapeutic targets. LncRNAs exhibit significant diagnostic and therapeutic potential, however, the biological significance of IncRNAs as a group remains unclear.

In order to elucidate the mechanisms of specific lncRNAs, systematic study is required. Therefore, the development of high-throughput, high-resolution imaging and experimental techniques to advance the study of lncRNAs is required. In addition, accelerating the development of bioinformatics and establishing relevant lncRNA databases is also essential. 
Future studies which track lncRNA localization throughout cellular compartments and across the genome are required to determine the structure of IncRNAs and to elucidate their key structure function relationships (65). In addition, in order to investigate the post-transcriptional modification functions of lncRNAs and to perturb the cellular levels of lncRNAs in a fast and efficient manner, studies that monitor the interactions of lncRNAs with nucleic acids and proteins are required (65). In the future, we hypothesize that lncRNAs will become important components for understanding, diagnosing and treating various cancers.

\section{Acknowledgements}

This study was supported by the National Natural Science Foundation of China (grant nos. 81302093, 81272752 and 81573747) and the Hong Kong Scholars Program (grant no. XJ2015033.

\section{References}

1. Yu FJ, Zheng JJ, Dong PH and Fan XM: Long non-coding RNAs and hepatocellular carcinoma. Mol Clin Oncol 3: 13-17, 2015.

2. Yao Y, Li J and Wang L: Large intervening non-coding RNA HOTAIR is an indicator of poor prognosis and a therapeutic target in human cancers. Int J Mol Sci 15: 18985-18999, 2014.

3. Zhang HM, Yang FQ, Yan Y, Che JP and Zheng JH: High expression of long non-coding RNA SPRY4-IT1 predicts poor prognosis of clear cell renal cell carcinoma. Int J Clin Exp Pathol 7: 5801-5809, 2014.

4. Hansji H, Leung EY, Baguley BC, Finlay GJ and Askarian-Amiri ME: Keeping abreast with long non-coding RNAs in mammary gland development and breast cancer. Front Genet 5: 379, 2014.

5. Liu Y, Zhang R, Qiu F, Li K, Zhou Y, Shang D and Xu Y: Construction of a lncRNA-PCG bipartite network and identification of cancer-related lncRNAs: A case study in prostate cancer. Mol BioSyst 11: 384-393, 2015.

6. Derrien T, Johnson R, Bussotti G, Tanzer A, Djebali S, Tilgner H, Guernec G, Martin D, Merkel A, Knowles DG, et al: The GENCODE v7 catalog of human long noncoding RNAs: Analysis of their gene structure, evolution and expression Genome Res 22: 1775-1789, 2012.

7. Chen LL and Carmichael GG: Long noncoding RNAs in mammalian cells: What, where and why? Wiley Interdiscip Rev RNA 1: 2-21, 2010.

8. Wilusz JE, Sunwoo H and Spector DL: Long noncoding RNAs: Functional surprises from the RNA world. Genes Dev 23: 1494-1504, 2009.

9. Fritah S, Niclou SP and Azuaje F: Databases for lncRNAs: A comparative evaluation of emerging tools. RNA 20: 1655-1665, 2014.

10. Cogill SB and Wang L: Co-expression network analysis of human IncRNAs and cancer genes. Cancer Inform 13 (Suppl 5): S49-S59, 2014.

11. Xu Y, Wang J, Qiu M, Xu L, Li M, Jiang F, Yin R and Xu L: Upregulation of the long noncoding RNA TUG1 promotes proliferation and migration of esophageal squamous cell carcinoma. Tumour Biol 36: 1643-1651, 2015.

12. Guo $\mathrm{H}$, Wu L, Yang Q, Ye $\mathrm{M}$ and Zhu X: Functional linc-POU3F3 is overexpressed and contributes to tumorigenesis in glioma. Gene 554: 114-119, 2015

13. Li W, Zheng J, Deng J, You Y, Wu H, Li N, Lu J and Zhou Y: Increased levels of the long intergenic non-protein coding RNA POU3F3 promote DNA methylation in esophageal squamous cell carcinoma cells. Gastroenterology 146: 1714-1726, 2014.

14. Li Q, Shao Y, Zhang X, Miao M, Qin L, Wang B, Ye G, Xiao B and Guo J: Plasma long noncoding RNA protected by exosomes as a potential stable biomarker for gastric cancer. Tumour Biol 36: 2007-2012, 2015.

15. Hu Y, Wang J, Qian J, Kong X, Tang J, Wang Y, Chen H, Hong J, Zou W, Chen Y, et al: Long noncoding RNA GAPLINC regulates CD44-dependent cell invasiveness and associates with poor prognosis of gastric cancer. Cancer Res 74: 6890-6902, 2014.
16. Ding J, Li D, Gong M, Wang J, Huang X, Wu T and Wang C: Expression and clinical significance of the long non-coding RNA PVT1 in human gastric cancer. Onco Targets Ther 7: 1625-1630, 2014.

17. Guo W, Dong Z, Bai Y, Guo Y, Shen S, Kuang G and Xu J: Associations between polymorphisms of HOTAIR and risk of gastric cardia adenocarcinoma in a population of north China. Tumour Biol 36: 2845-2854, 2015.

18. Xu TP, Huang MD, Xia R, Liu XX, Sun M, Yin L, Chen WM, Han L, Zhang EB, Kong R, et al: Decreased expression of the long non-coding RNA FENDRR is associated with poor prognosis in gastric cancer and FENDRR regulates gastric cancer cell metastasis by affecting fibronectin1 expression. J Hematol Oncol 7: 63, 2014.

19. Chen X, Sun J, Song Y, Gao P, Zhao J, Huang X, Liu B, Xu H and Wang Z: The novel long noncoding RNA AC138128.1 may be a predictive biomarker in gastric cancer. Med Oncol 31: 262, 2014

20. Rinn JL, Kertesz M, Wang JK, Squazzo SL, Xu X, Brugmann SA, Goodnough LH, Helms JA, Farnham PJ, Segal E and Chang HY: Functional demarcation of active and silent chromatin domains in human HOX loci by noncoding RNAs. Cell 129: 1311-1323, 2007.

21. Xue Y, Gu D, Ma G, Zhu L, Hua Q, Chu H, Tong N, Chen J, Zhang $\mathrm{Z}$ and Wang M: Genetic variants in IncRNA HOTAIR are associated with risk of colorectal cancer. Mutagenesis 30: 303-310, 2015.

22. Xue Y, Ma G, Gu D, Zhu L, Hua Q, Du M, Chu H, Tong N, Chen J, Zhang $\mathrm{Z}$ and Wang M: Genome-wide analysis of long noncoding RNA signature in human colorectal cancer. Gene 556: 227-234, 2015.

23. Wang P, Liu YH, Yao YL, Li Z, Li ZQ, Ma J and Xue YX: Long non-coding RNA CASC2 suppresses malignancy in human gliomas by miR-21. Cell Signal 27: 275-282, 2015.

24. Yin D, He X,Zhang E, Kong R, De W and Zhang Z: Long noncoding RNA GAS5 affects cell proliferation and predicts a poor prognosis in patients with colorectal cancer. Med Oncol 31: 253, 2014.

25. Xu X, Yuan J, Zuo Z, Yu Z, Liu Y and Fu C: Expression of long non-coding RNA associated with radiotherapy-resistance in colorectal cancer cell lines with different radiosensitivity. Zhonghua Wei Chang Wai Ke Za Zhi 17: 1096-1100, 2014 (In Chinese).

26. Cao C, Sun J, Zhang D, Guo X, Xie L, Li X, Wu D and Liu L: The long intergenic noncoding RNA UFC1, a target of microRNA $34 \mathrm{a}$, interacts with the mRNA stabilizing protein $\mathrm{HuR}$ to increase levels of $\beta$-catenin in $\mathrm{HCC}$ cells. Gastroenterology 148: 415-426 e18, 2015.

27. Yu W, Qiao Y, Tang X, Ma L, Wang Y, Zhang X, Weng W, Pan Q, $\mathrm{Yu}$ Y, Sun F and Wang J: Tumor suppressor long non-coding RNA, MT1DP is negatively regulated by YAP and Runx 2 to inhibit FoxA1 in liver cancer cells. Cell Signal 26: 2961-2968, 2014.

28. Ma MZ, Kong X, Weng MZ, Zhang MD, Qin YY, Gong W, Zhang WJ and Quan ZW: Long non-coding RNA-LET is a positive prognostic factor and exhibits tumor-suppressive activity in gallbladder cancer. Mol Carcinog 54: 1397-1406, 2015.

29. Pang EJ, Yang R, Fu XB and Liu YF: Overexpression of long non-coding RNA MALAT1 is correlated with clinical progression and unfavorable prognosis in pancreatic cancer. Tumour Biol 36: 2403-2407, 2015.

30. Jiao F, Hu H, Yuan C, Wang L, Jiang W, Jin Z, Guo Z and Wang L: Elevated expression level of long noncoding RNA MALAT-1 facilitates cell growth, migration and invasion in pancreatic cancer. Oncol Rep 32: 2485-2492, 2014.

31. Peng W, Gao W and Feng J: Long noncoding RNA HULC is a novel biomarker of poor prognosis in patients with pancreatic cancer. Med Oncol 31: 346, 2014.

32. Li J, Liu D, Hua R, Zhang J, Liu W, Huo Y, Cheng Y, Hong J and Sun Y: Long non-coding RNAs expressed in pancreatic ductal adenocarcinoma and lncRNA BC008363 an independent prognostic factor in PDAC. Pancreatology 14: 385-390, 2014.

33. Wang Y, Xu G, Chen W, Pan Q, Huang K, Pan J, Zhang W and Chen J: Detection of long-chain non-encoding RNA differential expression in non-small cell lung cancer by microarray analysis and preliminary verification. Mol Med Rep 11: 1925-1932, 2015.

34. Yang YR, Zang SZ, Zhong CL, Li YX, Zhao SS and Feng XJ: Increased expression of the lncRNA PVT1 promotes tumorigenesis in non-small cell lung cancer. Int J Clin Exp Pathol 7: 6929-6935, 2014.

35. Cheng N, Li X, Zhao C, Ren S, Chen X, Cai W, Zhao M, Zhang Y, Li J, Wang Q and Zhou C: Microarray expression profile of long non-coding RNAs in EGFR-TKIs resistance of human non-small cell lung cancer. Oncol Rep 33: 833-839, 2015. 
36. Liu Y, Luo F, Xu Y, Wang B, Zhao Y, Xu W, Shi L, Lu X and Liu Q: Epithelial-mesenchymal transition and cancer stem cells, mediated by a long non-coding RNA, HOTAIR, are involved in cell malignant transformation induced by cigarette smoke extract. Toxicol Appl Pharmacol 282: 9-19, 2015.

37. Loewen G, Jayawickramarajah J, Zhuo Y and Shan B: Functions of lncRNA HOTAIR in lung cancer. J Hematol Oncol 7: 90, 2014.

38. Shen L, Chen L, Wang Y, Jiang X, Xia H and Zhuang Z: Long noncoding RNA MALAT1 promotes brain metastasis by inducing epithelial-mesenchymal transition in lung cancer. J Neurooncol 121: 101-108, 2015

39. Luo J, Tang L, Zhang J, Ni J, Zhang HP, Zhang L, Xu JF and Zheng D: Long non-coding RNA CARLo-5 is a negative prognostic factor and exhibits tumor pro-oncogenic activity in non-small cell lung cancer. Tumour Biol 35: 11541-11549, 2014.

40. You QY, Tao H and Ling B: Long noncoding RNA HOX transcript antisense intergenic RNA (HOTAIR) as a foe and nove potential therapeutic target for endometrial carcinoma. Int J Gynecol Cancer 24: 1536, 2014.

41. Kim HJ, Lee DW, Yim GW, Nam EJ, Kim S, Kim SW and Kim YT: Long non-coding RNA HOTAIR is associated with human cervical cancer progression. Int J Oncol 46: 521-530, 2015.

42. Cao S, Liu W, Li F, Zhao W and Qin C: Decreased expression of lncRNA GAS5 predicts a poor prognosis in cervical cancer. Int J Clin Exp Pathol 7: 6776-6783, 2014

43. Kang L, Sun J, Wen X, Cui J, Wang G, Hoffman AR, Hu JF and $\mathrm{Li} \mathrm{W}$ : Aberrant allele-switch imprinting of a novel IGF1R intragenic antisense non-coding RNA in breast cancers. Eur J Cancer 51: 260-270, 2015

44. Su X, Malouf GG, Chen Y, Zhang J, Yao H, Valero V, Weinstein JN, Spano JP, Meric-Bernstam F, Khayat D and Esteva FJ: Comprehensive analysis of long non-coding RNAs in human breast cancer clinical subtypes. Oncotarget 5: 9864-9876, 2014.

45. Chi Y, Huang S, Yuan L, Liu M, Huang N, Zhou S, Zhou B and $\mathrm{Wu}$ J: Role of $\mathrm{BC} 040587$ as a predictor of poor outcome in breast cancer. Cancer Cell Int 14: 123, 2014

46. Gao Y, Meng H, Liu S, Hu J, Zhang Y, Jiao T, Liu Y, Ou J, Wang D, Yao L, et al: LncRNA-HOST2 regulates cell biological behaviors in epithelial ovarian cancer through a mechanism involving microRNA let-7b. Hum Mol Genet 24: 841-852, 2015.

47. Zhang HM, Yang FQ, Chen SJ, Che J and Zheng JH: Upregulation of long non-coding RNA MALAT1 correlates with tumor progression and poor prognosis in clear cell renal cell carcinoma. Tumour Biol 36: 2947-2955, 2015 .

48. Zhou W, Tao Z, Wang Z, Hu W, Shen M, Zhou L, Wen Z, Yu Z, Wu X and Huang K, et al: Long noncoding RNA PCA3 gene promoter region is related to the risk of prostate cancer on Chinese males. Exp Mol Pathol 97: 550-553, 2014.

49. Wang Y, Liu XJ and Yao XD: Function of PCA3 in prostate tissue and clinical research progress on developing a PCA3 score. Chin J Cancer Res 26: 493-500, 2014.

50. Hu CC, Gan P, Zhang RY, Xue JX and Ran LK: Identification of Prostate Cancer LncRNAs by RNA-Seq. Asian Pac J Cancer Prev 15: 9439-9444, 2014

51. Prensner JR, Chen W, Han S, Iyer MK, Cao Q, Kothari V, Evans JR, Knudsen KE, Paulsen MT, Ljungman M, et al: The long non-coding RNA PCAT-1 promotes prostate cancer cell proliferation through cMyc. Neoplasia 16: 900-908, 2014
52. Chakravarty D, Sboner A, Nair SS, Giannopoulou E, Li R, Hennig S, Mosquera JM, Pauwels J, Park K, Kossai M, et al: The oestrogen receptor alpha-regulated lncRNA NEAT1 is a critical modulator of prostate cancer. Nat Commun 5: 5383, 2014.

53. Li LJ, Zhu JL, Bao WS, Chen DK, Huang WW and Weng ZL: Long noncoding RNA GHET1 promotes the development of bladder cancer. Int J Clin Exp Pathol 7: 7196-7205, 2014.

54. Zhang K, Sun X, Zhou X, Han L, Chen L, Shi Z, Zhang A, Ye M, Wang Q, Liu C, et al: Long non-coding RNA HOTAIR promotes glioblastoma cell cycle progression in an EZH2 dependent manner. Oncotarget 6: 537-546, 2015.

55. Galasso M, Dama P, Previati M, Sandhu S, Palatini J, Coppola V, Warner S, Sana ME, Zanella R, Abujarour R, et al: A large scale expression study associates uc.283-plus lncRNA with pluripotent stem cells and human glioma. Genome Med 6: 76, 2014

56. Zeng C, Xu Y, Xu L, Yu X, Cheng J, Yang L, Chen S and Li Y: Inhibition of long non-coding RNA NEAT1 impairs myeloid differentiation in acute promyelocytic leukemia cells. BMC Cancer 14: 693, 2014

57. Cho SF, Chang YC, Chang CS, Lin SF, Liu YC, Hsiao HH, Chang JG and Liu TC: MALAT1 long non-coding RNA is overexpressed in multiple myeloma and may serve as a marker to predict disease progression. BMC Cancer 14: 809, 2014.

58. Dong Y, Liang G, Yuan B, Yang C, Gao R and Zhou X: MALAT1 promotes the proliferation and metastasis of osteosarcoma cells by activating the PI3K/Akt pathway. Tumour Biol 36: 1477-1486, 2015.

59. Pasic I, Shlien A, Durbin AD, Stavropoulos DJ, Baskin B, Ray PN, Novokmet A and Malkin D: Recurrent focal copy-number changes and loss of heterozygosity implicate two noncoding RNAs and one tumor suppressor gene at chromosome $3 \mathrm{q} 13.31$ in osteosarcoma. Cancer Res 70: 160-171, 2010.

60. Wang Y, Guo Q, Zhao Y, Chen J, Wang S, Hu J and Sun Y: BRAF-activated long non-coding RNA contributes to cell proliferation and activates autophagy in papillary thyroid carcinoma. Oncol Lett 8: 1947-1952, 2014.

61. Flockhart RJ, Webster DE, Qu K, Mascarenhas N, Kovalski J, Kretz M and Khavari PA: BRAFV600E remodels the melanocyte transcriptome and induces BANCR to regulate melanoma cell migration. Genome Res 22: 1006-1014, 2012.

62. Mazar J, Zhao W, Khalil AM, Lee B, Shelley J, Govindarajan SS, Yamamoto F, Ratnam M, Aftab MN, Collins S, et al: The functional characterization of long noncoding RNA SPRY4-IT1 in human melanoma cells. Oncotarget 5: 8959-8969, 2014.

63. Rahimy E, Kuo SZ and Ongkeko WM: Evaluation of non-coding RNAs as potential targets in head and neck squamous cell carcinoma cancer stem cells. Curr Drug Targets 15: 1247-1260, 2014.

64. Zhang Y, Liu G, Wang G, Zhong Q, Chen X, Fang J and Huang Z: Prediction of new long non-coding RNA of laryngeal carcinoma by high-throughput RNA-Seq data.Zhonghua Er Bi Yan Hou Tou Jing Wai Ke Za Zhi 49: 637-642, 2014 (In Chinese).

65. Sun M and Kraus WL: From discovery to function: The expanding roles of long non-coding RNAs in physiology and disease. Endocr Rev: Jan 7, 2015 (Epub ahead of print). 